\section{MRS Impact Award}

www.mrs.org/mrs-impact-award

The MRS Impact Award honors outstanding individuals who have displayed excellence in areas of science communication, education, advancing diversity, mentoring, or community engagement, which reflect the Society's pursuit to advance materials science and technology to improve the quality of life.

Each prize consists of a $\$ 5,000$ cash prize, an award trophy, a citation certificate, meeting registration fee to attend the MRS Spring Meeting, and a oneyear MRS membership. Additionally, reasonable travel and hotel expenses to attend the MRS Meeting will be reimbursed. (When a team is recognized, the cash prize will be split equally, but each individual shall receive a trophy and certificate.)

\section{MRS Woody White Service Award}

www.mrs.org/woody-white-nomination The MRS Woody White Service Award honors outstanding individuals who have embodied MRS' Mission, Vision and Values for an egalitarian interdisciplinary community advancing materials science and technology to improve the quality of life. It may be given in recognition of long-term, impactful service to the Society, as well as for special projects/programs that have significantly impacted the Society.
Nomination is open to individuals whose accomplishments fit within the scope of the award and must be a MRS member(s).

Any member of the MRS community, including members, volunteers, and staff, may nominate an individual or team of individuals for this award. The award consists of a certificate and a lifetime MRS membership, as well as a meeting registration waiver, and a travel stipend to attend the MRS Fall Meeting.

The deadline for submission of all award nominations is August 1, 2016. Visit www.mrs.org/awards for more information.

\title{
Preview: XXV International Materials Research Congress 2016
}

\section{August 14-19, 2016 • Cancún, Mexico \\ www.mrs.org/imrc-2016}

$\mathrm{T}$ he Materials Research Society (MRS) and the Sociedad Mexicana de Materiales (SMM) are excited to be working together on this global effort by growing the International Materials Research Congress (IMRC) held annually in Cancún, Mexico. The XXV IMRC will be held August 14-19, 2016. The Meeting Chairs are Jeff A. Eastman, Argonne National Laboratory (USA); Martin Heilmaier, Karlsruher Institut für Technologie, Institut für Angewandte Materialien (Germany); Olivia A. Graeve, University of California, San Diego (USA); and Manuel Ramos, Universidad Autónoma de Ciudad Juárez (Mexico).

The Congress will feature 39 symposia covering nanoscience and nanotechnologies, materials for energy applications, soft matter and biomaterials, structural materials, materials characterization, and general materials science. There will also be several tutorials ranging in topics from Fundamentals of CarbonBased Electrochemical Capacitors, to Thin-Film Photovoltaics: Materials and
Devices, to Texture Analysis; and Electron Backscatter Diffraction.

Hiroshi Amano, Nagoya University, Japan, will present the XXV IMRC Anniversary Lecture on "Blue LEDs and Future Electronics for Establishing Sustainable Society." Amano has more than 500 publications and 30 patents. $\mathrm{He}$ shared the Nobel Prize in Physics in 2014 with Isamu Akasaki and Shuji Nakamura.

Sergio Alcocer, president of the Mexican Academy of Engineering, Mexico, will present the Science, Technology, and Society Lecture: "The Importance of Materials Science and Engineering to Mexico's Competitiveness." The Academy has identified nine Grand Challenges for Mexican Engineering: competitiveness and innovation; education and research in engineering; energy and sustainability; food and rural development; health care; infrastructure, transportation, and cities; manufacturing and services; natural resources and climate change; and prospective and planning.
Plenary speakers at this year's event are Mark C. Hersam, Northwestern University, USA, "Mixed Dimensional Nanoelectronic Heterostructures"; Enrique J. Lavernia, University of California, Irvine, USA, "Nanostructured Metals and Composites: From the Nanoscale to the Microscale"; Tresa M. Pollock, University of California, Santa Barbara, USA, "Rapid Acquisition of 3D Data at the Mesoscale for Structural and Functional Materials"; Guus Rijnders, University of Twente, The Netherlands, "Novel Functionalities in Atomically Controlled Oxide Heterostrucures"; and Miguel José Yacamán, The University of Texas at San Antonio, USA, "From Metallurgy and Solid State Physics to Nanotechnology: 50 Years of Research on Materials."

This annual international meeting provides an interactive forum to discuss the advances in synthesis, characterization, properties, processing, applications, basic research trends, corrosion prevention, and more, all related to the area of materials science and engineering. It has become a popular meeting destination with approximately 1800 attendees from more than 40 countries.

Online registration ends August 10. For more information, visit the official IMRC website at www.mrs-mexico. org.mx/imrc2016/index.php. 